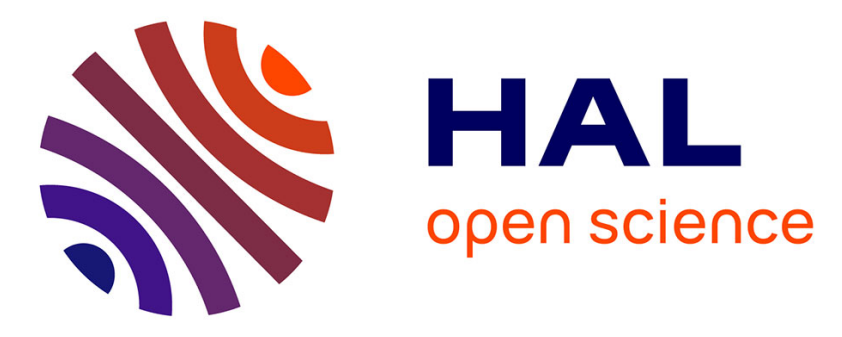

\title{
Towards model-based control of a steam Rankine process for engine waste heat recovery
}

Johan Peralez, Paolino Tona, Antonio Sciarretta, Pascal Dufour, Madiha

Nadri

\section{- To cite this version:}

Johan Peralez, Paolino Tona, Antonio Sciarretta, Pascal Dufour, Madiha Nadri. Towards model-based control of a steam Rankine process for engine waste heat recovery. 2012 IEEE Vehicle Power and Propulsion Conference (VPPC), Oct 2012, South Korea. pp.289 - 294, 10.1109/VPPC.2012.6422718 . hal-00875423

\section{HAL Id: hal-00875423 \\ https: / hal-ifp.archives-ouvertes.fr/hal-00875423}

Submitted on 22 Oct 2013

HAL is a multi-disciplinary open access archive for the deposit and dissemination of scientific research documents, whether they are published or not. The documents may come from teaching and research institutions in France or abroad, or from public or private research centers.
L'archive ouverte pluridisciplinaire $\mathbf{H A L}$, est destinée au dépôt et à la diffusion de documents scientifiques de niveau recherche, publiés ou non, émanant des établissements d'enseignement et de recherche français ou étrangers, des laboratoires publics ou privés. 


\section{Towards model-based control of a steam Rankine process for engine waste heat recovery}

\author{
Johan Peralez \\ Paolino Tona \\ and Antonio Sciarretta \\ IFP Energies Nouvelles \\ Control, Signal and System Department \\ Lyon site \\ Rond-point de l'échangeur de Solaize, BP 3 \\ 69360 Solaize, France
}

\author{
Pascal Dufour \\ and Madiha Nadri \\ Université de Lyon, F-69003, France \\ Université Lyon 1 \\ CNRS UMR 5007 \\ Laboratory of Process Control \\ and Chemical Engineering (LAGEP)
}

43 bd du 11 novembre, 69100 Villeurbanne, France

\begin{abstract}
Control plays a critical role in enabling good performance of Rankine processes for waste heat recovery from prime movers. Despite that, literature on control design for those systems is scarce, and there is a real need for investigating approaches that can be effective in an industrial context, where rapid control prototyping must be followed by a viable calibration procedure.

The paper describes modeling and control of a pilot Rankine steam process for exhaust gas heat recovery from a spark-ignition engine, focusing in particular on the use of a reduced-order dynamic model of the system to compute a nonlinear feedforward action to better control the system during nominal operation. Model reduction is obtained at the heat-exchanger level. First, via the moving-boundary approach, which avoids the need for complex, finite-volume, models. Then, via a further reduction of the resulting evaporator model which captures its dominant dynamics.
\end{abstract}

The proposed control system is validated on a detailed reference simulator using a demanding driving cycle.

\section{INTRODUCTION}

In the last few years, engine waste heat recovery (WHR) systems based on the Rankine thermodynamic cycle have been the focus of intensive research for road transportation applications. To mention a few examples, BMW and Ford have recently worked on this topic for cars, Cummins, Caterpillar, Daimler Trucks and Volvo for trucks [1]. The interest of manufacturers is justified by announced reductions in fuel consumption ranging from 5 to $10 \%$, depending on the system and the driving cycle.

Rankine processes for automotive applications apply the same principle used worldwide in industry to generate power: converting heat into work via the Rankine thermodynamic cycle. An external heat source supplies heat to a working fluid which circulates in a closed loop, via a heat exchanger (or a series of heat exchangers). Expansion of vaporized fluid (generally via a turbine) produces mechanical power. Vapor is then converted into liquid in a condenser which transfers heat to an external cold sink. A pump circulates the fluid at the required pressure.

In mobile applications, for the sake of compactness and weight saving, vaporization and superheating of the fluid usually take place in a single heat exchanger, the evaporator. The expansion machine, whether it is a turbine or a positive displacement expander, can deliver mechanical power directly to the transmission, even though most of the systems are designed to produce electricity via a generator connected to the auxiliary network and/or an energy storage system. But the main differences with stationary applications lie in the limited capacity of the cold sink and in the transient and uncontrollable behavior of the hot source, both depending on driving conditions. The latter two characteristics make the operation of those systems quite difficult. Eventually, fuel consumption gains may prove (much) lower than expected, if the heat recovery system has to be shut down too often and/or it takes too long to attain power production conditions. An effective control system is essential to attain satisfactory performance over a broad range of operating conditions.

Despite the importance of control in this context, few papers have been published on control design for Rankine-based WHR. Among them we can cite [2] (from Honda) which provides some experimental results on a steam process for SI engines, [3] on generic control issues and [4] which provides a complete startup and shut-down procedure for a Rankine cycle system with ethanol as working fluid, for heavy-duty applications. On the more general topic of Organic Rankine Cycles (ORC) for waste heat recovery operating with variable heat sources (not necessarily for transport applications), [5] covers dynamic modeling and control of an ORC system with R234fa as a working fluid. A somewhat richer literature is available on dynamic modelling and control of vapor compression cycles, the "reverse" of Rankine cycles ( [6], [7]). In both contexts, there is considerable interest in the development of simplified (moving-boundary, (MB)) models to reproduce two-phase behavior of heat exchanger without the complexity of the finite-volume approach ( [8], [9]).

A previous paper of ours [10], presents a practical supervision and control system for a pilot Rankine steam process for engine exhaust gas heat recovery. For nominal operation, when the system is in the power-production mode, an original control strategy is proposed, which focuses more on ensuring 
continuity of operation than on the pursuit of optimality and is implemented as a decentralized PI-control structure with static feedforward. In this paper, we propose a different control strategy, based on nonlinear model inversion, to enhance tracking and regulation performance in the power-production mode. The inverted model used to compute the feedforward part of control inputs comes from the reduction of a movingboundary model of the evaporator.

\section{SYSTEM DESCRIPTION}

The system under consideration is illustrated in Fig. 1.

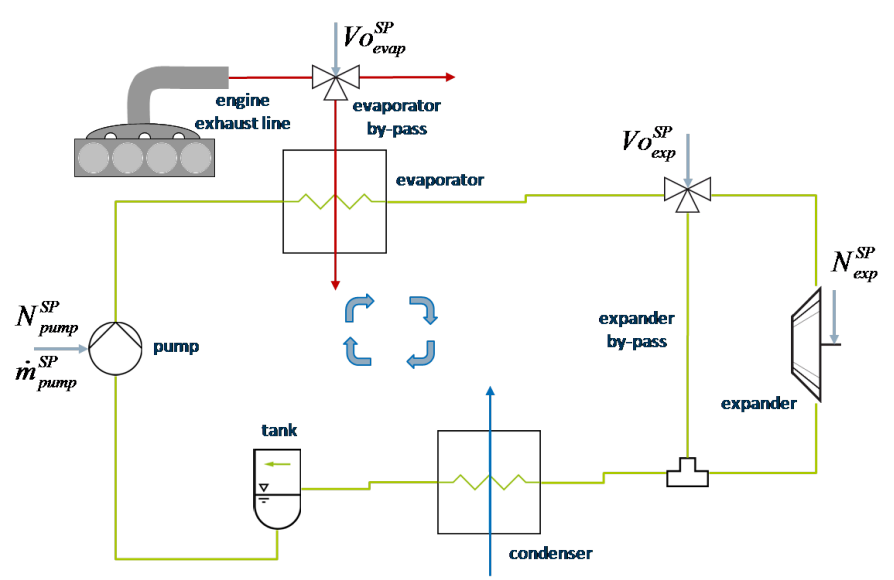

Fig. 1. Steam Rankine process under investigation

It is a pilot Rankine steam process for recovering waste heat from a SI engine on a test bench, designed to produce electric power via a positive-displacement expander connected to a generator (not shown). Expander speed can be adjusted by controlling generator load. The main manipulated variables (actuators) are shown in Fig. 2 (top left). Exhaust gas and condenser coolant conditions act as (measured) disturbances to the system. Main output variables are temperature - pressure pairs at each component inlet/outlet. The temperature pressure pairs can be used to compute relevant thermodynamic variables, such as superheating or subcooling.

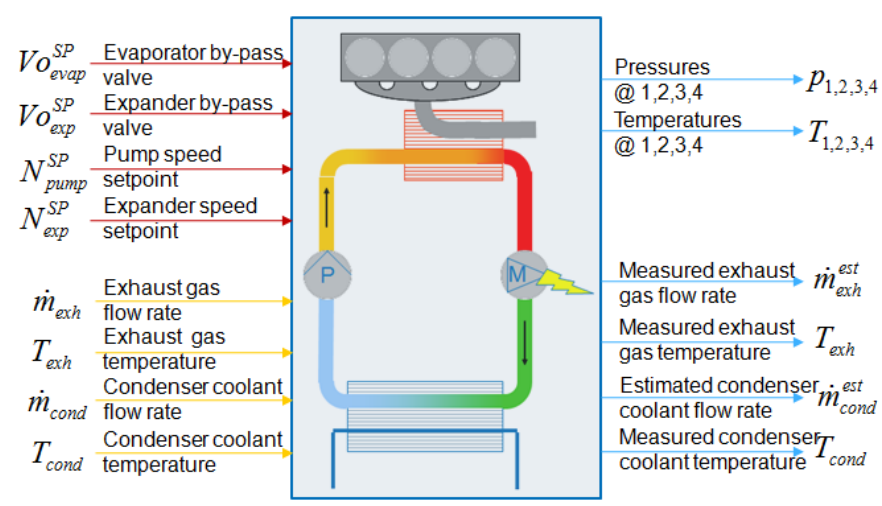

Fig. 2. Rankine steam process IO

\section{SYSTEM MODELING}

This section describes the modeling of the main components of the Rankine steam process. The models are written in the object-oriented, equation-based Modelica language, using Dymola.

The pump and the expander can be modeled via (standard) static equations, while the representation the complex two-phase behavior of heat exchangers requires nonstraightforward dynamic modeling. MB models have experimentally proven their abilities to describe dynamics of heat exchangers [6]. For Rankine systems, $7^{\text {th }}$-order MB models usually yield sufficient accuracy, which can only be obtained with a very dense discretization, resulting in a high number of dynamics states, when standard Finite Volume (FV) models are used [11].

\begin{tabular}{ll}
\hline Nomenclature & \\
Symbols & \\
$V$ & Volume $\left(\mathrm{m}^{3}\right)$ \\
$S$ & Area $\left(\mathrm{m}^{2}\right)$ \\
$\rho$ & Density $\left(\mathrm{kg} / \mathrm{m}^{3}\right)$ \\
$\alpha$ & Heat transfer coefficient $\left(\mathrm{W} /\left(\mathrm{m}^{2} \mathrm{~K}\right)\right)$ \\
$c$ & Heat capacity $(\mathrm{J} /(\mathrm{kg} \mathrm{K}))$ \\
$h$ & Specific enthalpy $(\mathrm{J} / \mathrm{kg})$ \\
$m$ & Mass $(\mathrm{kg})$ \\
$\dot{m}$ & Mass flow rate $(\mathrm{kg} / \mathrm{s})$ \\
$p$ & Pressure $(P a)$ \\
$T$ & Temperature $(\mathrm{K})$ \\
$L$ & Normalized zone length $(-)$ \\
$S H$ & Superheating $(\mathrm{K})$ \\
$N$ & Rotation speed $(\mathrm{rpm})$ \\
& \\
Subscripts & \\
evap & evaporator \\
exp & expander \\
exh & exhaust gas \\
$f$ & working fluid \\
$w$ & wall \\
$i$ & zone i \\
in & inlet \\
$v$ & outlet \\
$l$ & saturated vapor \\
\hline & saturated liquid \\
\hline &
\end{tabular}

\section{A. Evaporator}

The working fluid (water) enters the evaporator in the subcooled liquid phase and exits as superheated vapor. As shown by Fig. 3, MB models dynamically track the length of the fluid phases: normalized zone lengths $L_{1}, L_{2}, L_{3}$ respectively track liquid, two-phase and vapor zones (with $L_{3}=1-L_{1}-L_{2}$ due to normalization).

It is assumed in the following equations that pressure is homogeneous along the evaporator and conduction along the wall can be neglected. Then mass and energy balances can be applied to each of the 3 zones as follows: 


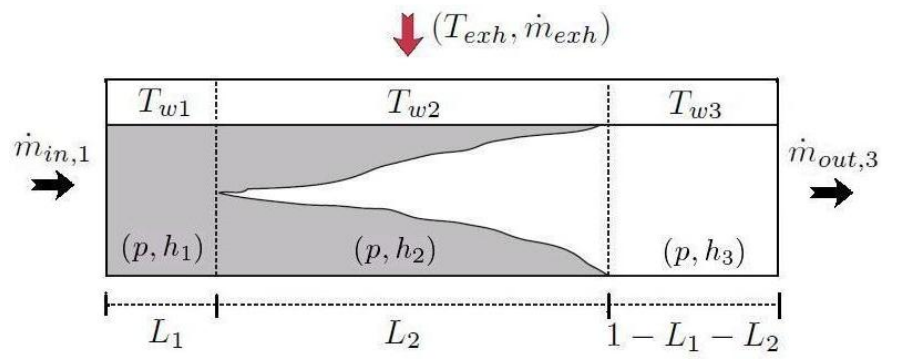

Fig. 3. Moving boundaries layout

1) Working fluid mass balance: For each zone $i$, water mass balance can be written $\frac{d m_{i}}{d t}=\dot{m}_{i n, i}-\dot{m}_{\text {out }, i}$, where $m_{i}=$ $\rho_{i} V_{f} L_{i}$ ( $\rho_{i}$ being the mean density of zone $i$ ). Considering $L_{i}$ as time variant and density $\rho_{i}$ as a function of pressure and enthalpy, yields:

$\rho_{i} V_{f} \frac{d L_{i}}{d t}+\left(\left.\frac{\partial \rho}{\partial p}\right|_{h_{i}} \frac{d p}{d t}+\left.\frac{\partial \rho}{\partial h}\right|_{p} \frac{d h_{i}}{d t}\right) V_{f} L_{i}=\dot{m}_{\text {in }, i}-\dot{m}_{\text {out }, i}$

where $h_{i}$ is the mean enthalpy of zone $i$. For single phase zones (liquid or vapor), $h_{i}=\frac{h_{\text {in }}+h_{\text {out }}}{2}$ and for two-phase zone void fraction [12] can be introduced. Here, density $\rho_{i}$, and its partial derivatives $\left.\frac{\partial \rho}{\partial p}\right|_{h_{i}},\left.\frac{\partial \rho}{\partial h}\right|_{p}$ are fluid properties, computed from the pair $\left(p, h_{i}\right)$.

2) Working fluid energy balance: Using the same approach, energy balance for water in each zone yields:

$$
\begin{gathered}
\rho_{i} V_{f} L_{i} \frac{d h_{i}}{d t}=\dot{m}_{i n, i}\left(h_{i n, i}-h_{i}\right)-\dot{m}_{\text {out }, i}\left(h_{\text {out }, i}-h_{i}\right) \\
+\dot{Q}_{f, i} L_{i}+\frac{d p}{d t} V_{f} L_{i}
\end{gathered}
$$

where $\dot{Q}_{f, i}=S_{f} \alpha_{i}\left(T_{w, i}-T_{f, i}\right)$ represents heat transfer from wall.

3) Wall energy balance: For the wall, energy balance yields:

$$
m_{w} c_{w} \frac{d T_{w, i}}{d t}=\dot{Q}_{e x h, i}-\dot{Q}_{f, i}
$$

where $\dot{Q}_{e x h, i}=\dot{m}_{e x h} c_{e x h}\left(1-\exp \left(-\frac{\alpha_{e x h} S_{e x h}}{\dot{m}_{e x h} c_{e x h}}\right)\right)\left(T_{e x h}-\right.$ $\left.T_{w, i}\right)$ represents heat transfer from exhaust gas.

4) Differential algebraic equations (DAE) system: the equations introduced above are completed by interface equations. Fluid enthalpies and mass flows at zones 2-3 inlet correspond to zones 1-2 outlet; i.e $\dot{m}_{i n, i+1}=\dot{m}_{i n, i}$ and $h_{i n, i+1}=h_{i n, i}$ for $i=1,2$. For the two-phase zone, inlet and outlet enthalpies correspond to saturation values $\left(h_{i n, 2}=h_{l}\right.$ and $h_{\text {out }, 2}=h_{v}$ ). Finally the balance and interface equations constitute a DAE system with 7 dynamic states $\left(T_{w, 1}, T_{w, 2}\right.$, $\left.T_{w, 3}, p, L_{1}, L_{2}, h_{3}\right)$

\section{B. Condenser and tank}

Condenser equations are based on the same principles used to obtain evaporator equations. Water enters the condenser in vapor phase and is assumed exiting in liquid phase. Tank model captures the dynamics of fluid temperature and volume (due to changes in working fluid densities along the system).

\section{Pump and expander}

Because pump and expander dynamics are very fast compared to others components, a static model is used for them.

In the volumetric expander, volumetric flow rate can be assumed proportional to rotation speed $N_{\text {exp }}$ [2]. Then mass flow rate is given by

$$
\dot{m}_{\text {exp }}=N_{\text {exp }} \rho \eta_{\text {exp }} V_{\text {exp }}
$$

where $\rho$ is the fluid density at evaporator outlet, $V_{\exp }$ the expander displacement and $\eta_{\exp }$ the volumetric efficiency (assumed constant). The isentropic efficiency is also assumed to be constant.

The pump provides a mass-flow rate $\dot{m}_{\text {pump }}$ at the evaporator inlet.

\section{MODEL REDUCTION FOR CONTROL}

The MB modeling approach for heat exchangers of thermofluid systems, implementing vapor-compression or Rankine cycles, generally yields a $7^{\text {th }}$ order model, when three zones are represented [12], [8]. Linearized MB models can be used for control: [13] shows that a state feedback is able to ensure stability around an operating point.

However, in Rankine systems for automotive applications, it is difficult to obtain good performance with a Linear Time Invariant (LTI) controller, for a realistic road cycle. Not only do these systems have to deal with strong disturbances from the hot source (exhaust gas), but the evaporator also presents strong non-linearities depending on the external conditions. Better performance can be expected using nonlinear control methods.

The full-order MB model of the evaporator introduced before, while simpler than FV models, is still too complex to be used for nonlinear control design in a straightforward way. This is why we have tried to capture its dominant dynamics in some reduced-order (non-linear) models.

\section{A. Evaporator model reduction}

Well-known reduction methods can be applied to a linearized MB model. In [14], the authors apply four reduction algorithms to the linearized model of an evaporator of an Organic Rankine Cycle for waste heat recovery.

A low-order non-linear model for the evaporator of a refrigeration system, based on a MB approach with two zones (vapor and two-phase), has been presented in [15]. However, in a Rankine cycle, the liquid zone always exists and has significant weight. [12] analyzes dominant time constants of evaporators and proposes a physical interpretation. Although the values of these time constants depend on operating points and system design (especially on volumes and working fluid type), fast and slow modes can be separated for typical evaporators. Slowest modes correspond to wall temperatures $T_{w i}$ dynamics 
and, because the liquid zone contains most of the fluid mass, dynamic of liquid zone length $L_{1}$ is also slow.

[16] proposes a discretization method for one-dimensional distributed parameters systems. This method consists in partitioning volumes into dynamic and static ones. It results in loworder models (though with a significant algebraic part) with the same steady states as the reference models. [16] applies it to a heat exchanger where fluid is assumed incompressible.

Adapting this concept to MB models, we propose hereafter two reduced models with three and four dynamic states, respectively with $\left[\begin{array}{llll}T_{w 1} & T_{w 2} & T_{w 3}\end{array}\right]^{\prime}$ and $\left[\begin{array}{llll}T_{w 1} & T_{w 2} & T_{w 3} & L_{1}\end{array}\right]^{\prime}$ as state vector. The reference MB model considered is the $7^{\text {th }}$-order model described in Section III-A. Fastest modes are approximated by static variables (namely $p, L_{2}$ and $h_{3}$ ).

Under these assumptions, mass balance (1) can be rewritten as follows:

- for the liquid zone:

$$
\left.0.5 V_{f} L_{1} \frac{\partial \rho}{\partial h}\right|_{p} \dot{h}_{i n}+\rho_{1} V_{f} \frac{d L_{1}}{d t}=\dot{m}_{\text {in }, 1}-\dot{m}_{\text {out }, 1}
$$

- for the two-phase zone:

$$
0=\dot{m}_{\text {in }, 2}-\dot{m}_{\text {out }, 3}
$$

- for the vapor zone:

$$
-\rho_{3} V_{f} \frac{d L_{1}}{d t}=\dot{m}_{i n, 3}-\dot{m}_{\text {out }, 3}
$$

Energy balance is rewritten for water in the same way, while wall energy balance (3) is conserved. Finally, the $4^{\text {th }}$-order model is described by the following DAE system:

$$
\left\{\begin{array}{c}
m_{w} c_{w} \frac{d T_{w, i}}{d t}=\dot{Q}_{e x h, i}-\dot{Q}_{f, i}, i=1,2,3 \\
0=\left.0.5 V_{f} L_{1} \frac{\partial \rho}{\partial h}\right|_{p} \dot{h}_{i n, 1}+\rho_{1} V_{f} \frac{d L_{1}}{d t}-\dot{m}_{\text {in }, 1}+\dot{m}_{\text {out }, 1} \\
0=\dot{m}_{\text {in }, 2}-\dot{m}_{\text {out }, 3} \\
-\rho_{3} V_{f} \frac{d L_{1}}{d t}=\dot{m}_{\text {in }, 3}-\dot{m}_{\text {out }, 3} \\
0=-0.5 V_{f} \rho_{1} L_{1} \dot{h}_{\text {in }, 1}+0.5\left(\dot{m}_{\text {in }, 1}+\dot{m}_{\text {out }, 1}\right)\left(h_{\text {in }, 1}-h_{l}\right) \\
+\dot{Q}_{f, 1} L_{1} \\
0=0.5\left(\dot{m}_{\text {in }, 2}+\dot{m}_{\text {out }, 2}\right)\left(h_{l}-h_{v}\right)+\dot{Q}_{f, 2} L_{2} \\
0=0.5\left(\dot{m}_{\text {in }, 3}+\dot{m}_{\text {out }, 3}\right)\left(h_{v}-h_{\text {out }}\right)+\dot{Q}_{f, 3}\left(1-L_{1}-L_{2}\right)
\end{array}\right.
$$

where $\dot{Q}_{f, i}, \dot{Q}_{e x h, i}$ and interface equations are unchanged with respect to the reference MB model (Section III-A).

With $L_{1}$ approximated as a static variable, mass balance can be written as $\dot{m}_{i n, i}=\dot{m}_{o u t, i}$ for $i=1,2,3$. Thus, the $3^{r d}$-order model is described by the following DAE system:

$$
\left\{\begin{array}{c}
m_{w} c_{w} \frac{d T_{w, i}}{d t}=\dot{Q}_{e x h, i}-\dot{Q}_{f, i}, i=1,2,3 \\
0=-0.5 V_{f} \rho_{1} L_{1} \dot{h}_{i n}+\dot{m}_{i n, 1}\left(h_{i n, 1}-h_{l}\right)+\dot{Q}_{f, 1} L_{1} \\
0=\dot{m}_{\text {in }, 1}\left(h_{l}-h_{v}\right)+\dot{Q}_{f, 2} L_{2} \\
0=\dot{m}_{i n, 1}\left(h_{v}-h_{o u t, 3}\right)+\dot{Q}_{f, 3}\left(1-L_{1}-L_{2}\right)
\end{array}\right.
$$

\section{B. Validation of reduced-order models}

In order to compare the reduced models with the reference MB models, evaporator models are connected with pump and expander described in Section III-C. Their responses in terms of pressure and outlet superheating are compared in Fig. 4, for varying input conditions. The variations on control and disturbance inputs are as follows: at $t=100 \mathrm{~s}, 600 \mathrm{~s}, 1100 \mathrm{~s}$ steps are performed respectively on pump mass flow, exhaust mass flow and exhaust temperature. Plots confirm that steadystate behavior of reduced and reference models are similar. The $3^{r d}$-order model reproduce perfectly slower dynamics but not sufficiently fast. The $4^{\text {th }}$-order model dynamic behavior is very close to the reference MB. In particular, the inverse responses are well reproduced.

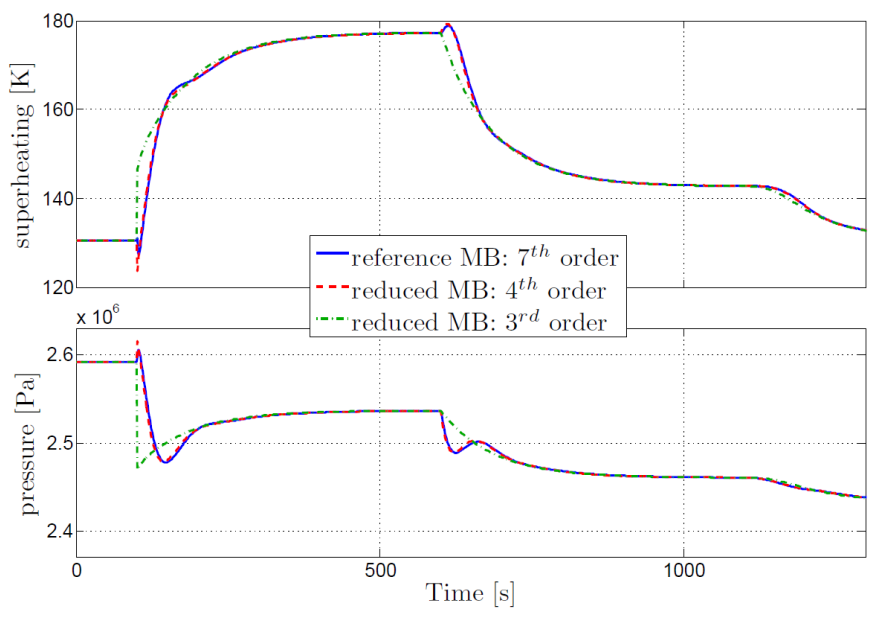

Fig. 4. Open loop response of full-order and reduced models to varying input conditions

\section{CONTROL}

The overall control structure for the Rankine pilot process is the same as in [10]. It is a hierarchical structure, coded in Simulink, with modules for sensors and actuators management, for system supervision and control. In nominal mode, when power is produced, evaporator and expander by-pass are closed, and two actuators are available to control the Rankine process: $N_{\text {pump }}$ or (indirectly) $\dot{m}_{\text {pump }}$ and $N_{\text {exp }}$. Pressure $p$ and superheating $S H$ at evaporator outlet are the controlled outputs. Those variables must track setpoints chosen so as to ensure safety and maximize produced power, despite varying external conditions.

\section{A. Limits of decentralized PI control}

The pragmatic control approach for the Rankine process in power-production mode followed in [10] consisted in the following steps:

- identifying the two-input two-output (TITO) transfer matrix of the system, with $\dot{m}_{\text {pump }}$ and $N_{\text {exp }}$ as inputs, and pressure $p$ and superheating $S H$ as outputs;

- finding the appropriate input-output pairing via (dynamic) relative gain analysis (RGA); 


\begin{tabular}{|c|c|c|c|c|c|}
\hline \multicolumn{3}{|c|}{ "Hot" operating point } & \multicolumn{3}{|c|}{ "Cold" operating point } \\
\hline$y^{0}$ & $\begin{array}{l}S H \\
p\end{array}$ & $\begin{array}{l}200 \mathrm{~K} \\
2.5 \mathrm{MPa}\end{array}$ & $y^{0}$ & $\begin{array}{l}S H \\
p\end{array}$ & $\begin{array}{l}200 \mathrm{~K} \\
2.5 \mathrm{MPa}\end{array}$ \\
\hline$u_{2}^{0}$ & $\begin{array}{l}\dot{m}_{\text {pump }} \\
N_{\text {exp }} \\
\end{array}$ & $\begin{array}{l}0.005855 \mathrm{~kg} / \mathrm{s} \\
712.5 \mathrm{rpm}\end{array}$ & $u_{1}^{0}$ & $\begin{array}{l}\dot{m}_{\text {pump }} \\
N_{\text {exp }}\end{array}$ & $\begin{array}{l}0.0010156 \mathrm{~kg} / \mathrm{s} \\
134.3 \mathrm{rpm}\end{array}$ \\
\hline$d_{2}^{0}$ & $\begin{array}{l}T_{\text {exh }} \\
\dot{m}_{\text {exh }} \\
T_{i n} \\
\end{array}$ & $\begin{array}{l}600^{\circ} \mathrm{C} \\
0.05 \mathrm{~kg} / \mathrm{s} \\
70^{\circ} \mathrm{C}\end{array}$ & $d_{1}^{0}$ & $\begin{array}{l}T_{\text {exh }} \\
\dot{m}_{\text {exh }} \\
T_{i n} \\
\end{array}$ & $\begin{array}{l}400^{\circ} \mathrm{C} \\
0.02 \mathrm{~kg} / \mathrm{s} \\
30^{\circ} \mathrm{C}\end{array}$ \\
\hline
\end{tabular}

TABLE I

DEFINITION OF "HOT" AND “COLD” OPERATING POINTS
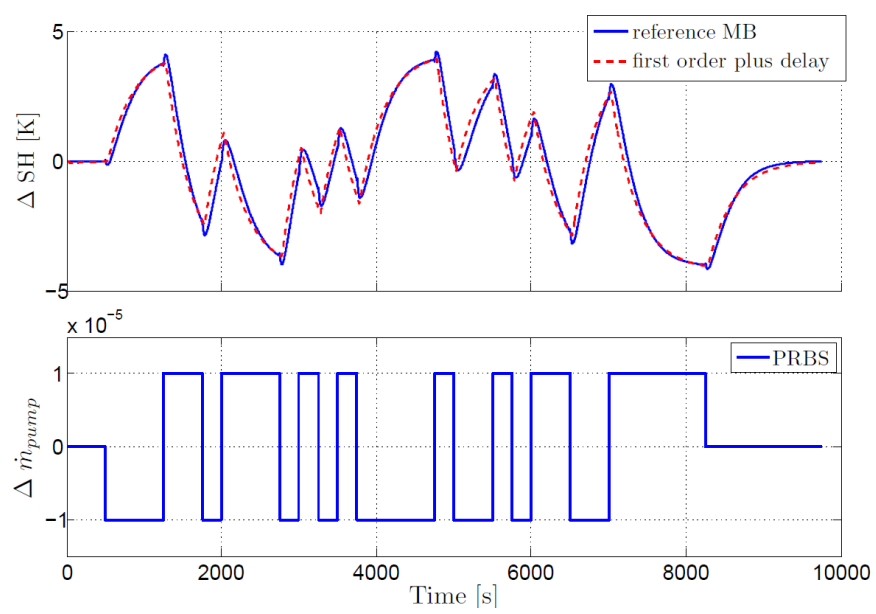

Fig. 5. Validation of FOPTD model for the $\left\{\dot{m}_{\text {pump }}-S H\right\}$ pair on the "cold" operating point

- designing a decentralized PI control system using the diagonal terms of the TITO transfer matrix.

The problem with this control structure, and similar ones encountered in literature [2], [5], is that identified linear models for thermo-fluid systems are very sensitive to external conditions. Let us consider the two operating points described in TABLE I, with the same system outputs $y^{0}$, obtained for different ("hot" and "cold") exhaust gas conditions met during a typical driving cycle.The dynamic relation between $\dot{m}_{\text {pump }}$ and $S H$ can be fairly well described (around an operating point) by a first order plus time delay (FOPTD) model $\frac{Y(s)}{U(s)}=\frac{K_{p}}{1+\tau_{p} s} e^{-T_{p} s}$. This is confirmed by validation results of a FOPTD model identified on the reference MB model, shown in Fig. 5.

However, as the system has strongly non-linearities, the FOPTD parameters change a lot for the two operating points (TABLE II). A conservative (slow) PI feedback is thus required to preserve stability in the presence of model mismatch (long delays in superheating response to pump variations are particularly harmful). In this context, accurate tracking of arbitrary setpoints is impossible. In [10], in order to obtain acceptable results on a realistic driving cycle, we have to both detune the PI controllers and add a static feedforward action on the pump. This helps to improve superheat control performance and to generate sustainable setpoints, favoring the continuity of operation over the search for optimality.

\begin{tabular}{|c|c|c|c|}
\cline { 2 - 4 } \multicolumn{1}{c|}{} & $K_{p}$ & $\tau_{p}$ & $T_{p}$ \\
\hline "Hot" operating point & $-1.36 e^{5} \mathrm{~K} / \mathrm{kg} . \mathrm{s}$ & $60.1 \mathrm{~s}$ & $8.4 \mathrm{~s}$ \\
\hline "Cold" operating point & $-4.28 e^{5} \mathrm{~K} / \mathrm{kg} . \mathrm{s}$ & $345 \mathrm{~s}$ & $30 \mathrm{~s}$ \\
\hline
\end{tabular}

TABLE II

IDENTIFIED MODEL PARAMETERS AROUND THE TWO OPERATING POINTS

\section{B. Nonlinear inversion-based control}

Fig. 6 shows the structure of the new controller we propose for the Rankine steam process. The inverse of a system model in the feedforward path computes the input trajectories $u_{d}$ corresponding to the desired system outputs (setpoints $y^{S P}$ ), given the current disturbances $d$. A decentralized feedback controller applies a correction on $u_{d}$ so as to $y$ tracks $y^{S P}$ in the presence of model uncertainty. Notice that, among the disturbances, $T_{e x h}$ and $T_{i n}$ are easily measurable, while an estimation of $\dot{m}_{e x h}$ can be provided by the engine control unit.

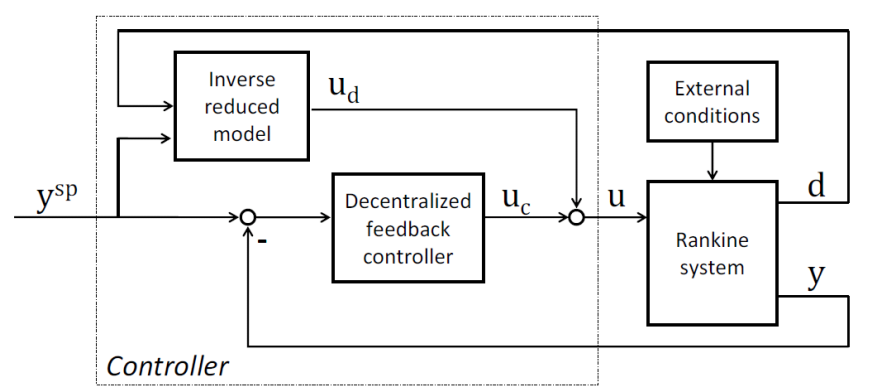

Fig. 6. Controller with inverse of reduced-model in the feedforward path.

The $4^{\text {th }}$-order reduced model is more accurate than the $3^{\text {th }}$-order one but cannot be inverted exactly because it is non-minimum phase. So the $3^{t h}$-order reduced model will be used. Evaporator mass flow (considered as homogeneous in the $3^{r d}$-order model) can be explicitly computed from the DAE system (9). It constitutes the feedforward part $u_{1, d}$ of the first control input $u_{1}=\dot{m}_{\text {pump }}$. Expander rotational speed can be explicitly computed from equation (4). It constitutes the feedforward part $u_{2, d}$ of the second control input $u_{2}=N_{\text {exp }}$.

This yields the following equation system for dynamic feedforward:

$$
\left\{\begin{array}{c}
\frac{d T_{w, i}}{d t}=\frac{\dot{Q}_{e x h, i}-\dot{Q}_{f, i}}{m_{w} c_{w}}, i=1,2,3 \\
u_{1, d}=\frac{\left(T_{3}-T_{w 3}\right) S_{R} \alpha_{3}}{h_{v}-h_{o u t}+\frac{\left(T_{3}-T w_{3}\right)\left(h_{l} h_{i n}\right)_{3}}{\alpha_{1}\left(T w_{1}-T_{1}\right)}+\frac{\left(T_{3}-T w_{3}\right)\left(h_{v}-h_{l}\right) \alpha_{3}}{\alpha_{2}\left(T w_{2}-T_{2}\right)}} \\
u_{2, d}=\frac{u_{1, d}}{\rho_{\text {out }, 3} \eta_{\text {exp }} V_{\text {exp }}}
\end{array}\right.
$$

where fluid properties $h_{v}, h_{l}, T_{i}$ and $\rho_{\text {out }, 3}$ are determined from desired outputs $\left(p^{S P}\right.$ and $\left.S H^{S P}\right)$.

\section{RESUlts}

Since, at the time of writing, the test bench set-up has not been finalized yet, the proposed nonlinear inversion-based control strategy is validated using the reference Rankine steam 
process simulator in Dymola using the real-time control software in Simulink, which will be eventually implemented on the test-bench. Exhaust gas conditions come from experimental data (Fig. 7), recorded from the 2.0-liter turbocharged SI engine of a Renault Megane SCENIC II on a highway driving cycle (the Artemis Motorway Cycle). This paper focusing on nominal conditions, simulation starts on hot conditions (water at evaporator outlet is assumed to be superheated steam).

In order to asses tracking performance, set points ( $p^{S P}$ and $S H^{S P}$ ) are increased during simulation (Fig. 8). The control system ensures tight tracking of steam pressure, regardless of highly-varying exhaust conditions. Steam superheat is also fairly well controlled, with maximum absolute error of $7 \mathrm{~K}$.

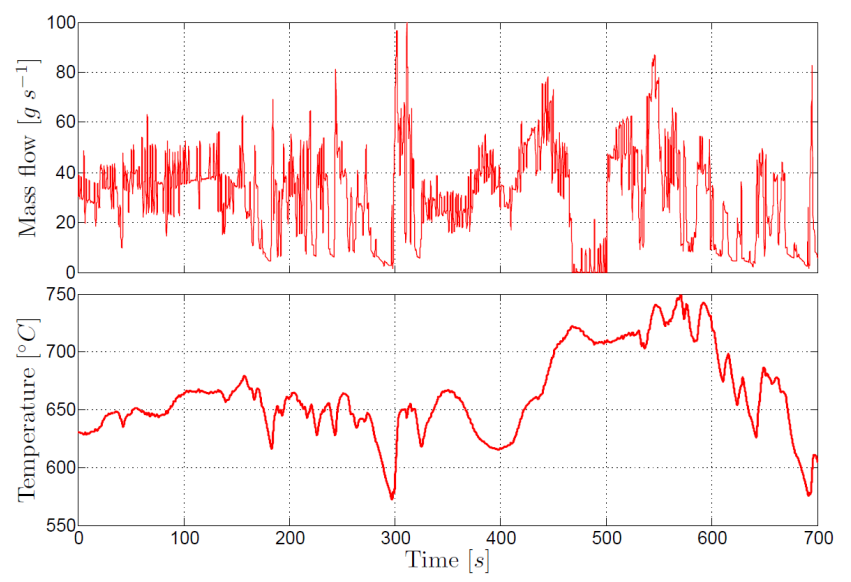

Fig. 7. Exhaust conditions (Artemis cycle)

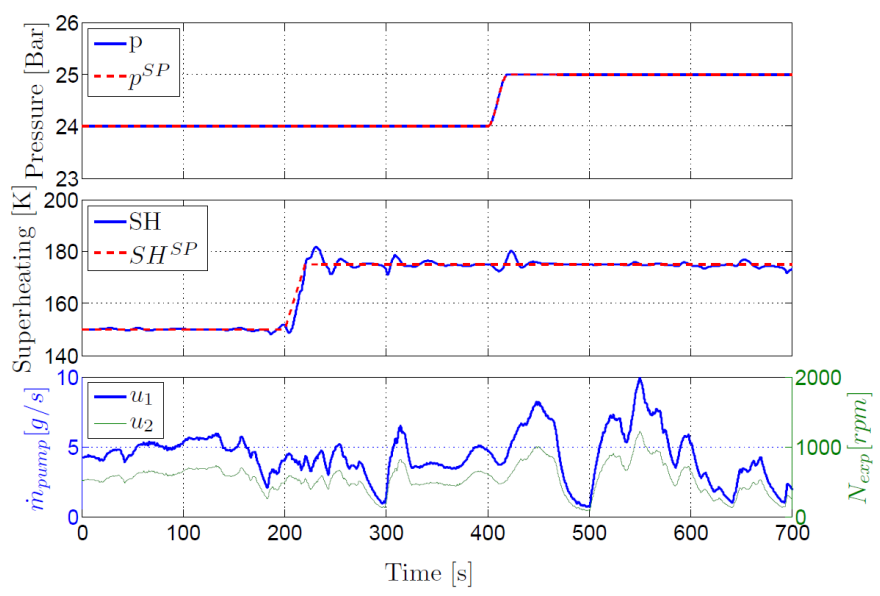

Fig. 8. Pressure and superheating regulation by nonlinear inversion-based control

\section{CONCLUSION}

This paper reports two original reduced models of evaporator used in a Rankine steam process for waste heat recovery from a SI engine. The $3^{r d}$-order reduced model is subsequently used to design a nonlinear inversion-based controller. This nonlinear model-based controller has the potential to overcome, on this kind of system, the shortcomings of LTI controllers and more particularly of the decentralized PI control strategies that are most often found in the literature.

Simulation on a demanding driving cycle confirms its ability to efficiently track pressure and superheating setpoints, allowing to pursue desired conditions at expander inlet in spite of disturbances (exhaust gas transients). Of course, an assessment on the experimental test bench will be necessary.

Further research will mostly focus on the expander: finding (dynamic) optimal conditions at expander inlet and considering possible saturations in its rotational speed.

\section{REFERENCES}

$\begin{array}{lccc}\text { [1] DEER, } & \text { "Directions } & \text { in } & \begin{array}{c}\text { Engine-Efficiency } \\ \text { Conference }\end{array} \\ \text { Emissions } & \text { Research } & & \text { and }\end{array}$ http://www1.eere.energy.gov/vehiclesandfuels/resources/proceedings/ index.html.

[2] T. Endo, S. Kawajiri, Y. Kojima, K. Takahashi, T. Baba, S. Ibaraki, T. Takahashi, and M. Shinohara, "Study on maximizing exergy in automotive engines," in SAE 2007 World Congress, no. 2007-01-0257, Detroit, MI, USA, Apr 2007.

[3] R. Stobart, S. Hounsham, and R. Weerasinghe, "The controllability of vapour based thermal recovery systems in vehicles," in SAE 2007 World Congress, no. 2007-01-0270, Detroit, MI, USA, Apr 2007.

[4] T. Park, H. Teng, G. Hunter, and B. e. a. van der Velde, "A rankine cycle system for recovering waste heat from HD diesel engines-experimental results," in SAE 2011 World Congress, no. 2011-01-1337, Detroit, MI, USA, Apr 2011.

[5] S. Quoilin, R. Aumann, A. Grill, A. Schuster, V. Lemort, and H. Spliethoff, "Dynamic modeling and optimal control strategy of waste heat recovery organic rankine cycles," Journal of Applied Energy, 2011.

[6] B. Rasmussen, "Dynamic modeling and advanced control of air conditioning and refrigeration systems," Ph.D. dissertation, University of Illinois at Urbana-Champaign, 2005.

[7] A. Alleyne, B. Rasmussen, M. Keir, and B. Eldredge, "Advances in energy systems modeling and control," in American Control Conference, 2007. ACC'07. IEEE, 2007, pp. 4363-4373.

[8] M. Gräber, N. Strupp, and W. Tegethoff, "Moving boundary heat exchanger model and validation procedure," in EUROSIM Congress on Modelling and Simulation, Prague, Czech Republic, 2010.

[9] D. Wei, X. Lu, Z. Lu, and J. Gu, "Dynamic modeling and simulation of an organic rankine cycle (orc) system for waste heat recovery," Journal of Applied thermal engineering, vol. 28, no. 10, pp. 1216-1224, 2008.

[10] P. Tona, J. Peralez, and A. Sciarretta, "Supervision and control prototyping for an engine exhaust gas heat recovery system based on a steam rankine cycle," in 2012 IEEE/ASME International Conference on Advanced Intelligent Mechatronics (AIM 2012), KaoHsiung, Taiwan, jul 2012.

[11] D. Wei, X. Lu, Z. Lu, and J. Gu, "Performance analysis and optimization of organic rankine cycle (orc) for waste heat recovery," Energy Conversion and Management, vol. 48, no. 4, pp. 1113 - 1119, 2007.

[12] J. Jensen, "Dynamic modeling of thermo-fluid systems with focus on evaporators for refrigeration," Ph.D. dissertation, Technical University of Denmark, 2003.

[13] J. Zhang, W. Zhang, G. Hou, and F. Fang, "Dynamic modeling and multivariable control of organic rankine cycles in waste heat utilizing processes," Computers \& Mathematics with Applications, no. 0, pp. -, 2012.

[14] R. Wang, X. Zhao, C. Wang, and Y. Li, "Modeling and model order reduction of evaporator in organic rankine cycle for waste heat recovery," in Advanced Mechatronic Systems (ICAMechS), 2011 International Conference on. IEEE, 2011, pp. 291-296.

[15] T. Cheng, X. He, and H. Asada, "Nonlinear observer design for twophase flow heat exchangers of air conditioning systems," in American Control Conference, 2004. Proceedings of the 2004, vol. 2. IEEE, 2004, pp. 1534-1539.

[16] A. Linhart and S. Skogestad, "An aggregation model reduction method for one-dimensional distributed systems," AIChE Journal, 2010. 